\title{
Impact of observed North Atlantic multidecadal variations to European summer climate: a linear baroclinic response to surface heating
}

\author{
Rohit Ghosh ${ }^{1} \cdot$ Wolfgang A. Müller ${ }^{2} \cdot$ Johanna Baehr $^{3} \cdot$ Jürgen Bader $^{2}$
}

Received: 11 September 2015 / Accepted: 16 July 2016

(C) The Author(s) 2016. This article is published with open access at Springerlink.com

\begin{abstract}
The observed prominent multidecadal variations in the central to eastern (C-E) European summer temperature are closely related to the Atlantic multidecadal variability (AMV). Using the Twentieth Century Reanalysis project version 2 data for the period of 1930-2012, we present a mechanism by which the multidecadal variations in the C-E European summer temperature are associated to a linear baroclinic atmospheric response to the AMV-related surface heat flux. Our results suggest that over the northwestern Atlantic, the positive heat flux anomaly triggers a surface baroclinic pressure response to diabatic heating with a negative surface pressure anomaly to the east of the heat source. Further downstream, this response induces an east-west wave-like pressure anomaly. The east-west wave-like response in the sea level pressure structure, to which we refer as North-Atlantic-European East West (NEW) mode, is independent of the summer North Atlantic Oscillation and is the principal mode of variations during summer over the Euro-Atlantic region at multidecadal
\end{abstract}

Rohit Ghosh

rohit.ghosh@mpimet.mpg.de

Wolfgang A. Müller

wolfgang.mueller@mpimet.mpg.de

Johanna Baehr

johanna.baehr@zmaw.de

Jürgen Bader

juergen.bader@mpimet.mpg.de

1 International Max Planck Research School on Earth System Modelling, Max Planck Institute for Meteorology, Hamburg, Germany

2 Max Planck Institute for Meteorology, Hamburg, Germany

3 Institute of Oceanography, University of Hamburg, Hamburg, Germany time scales. The NEW mode causes warming of the C-E European region by creating an atmospheric blocking-like situation. Our findings also suggest that this NEW mode is responsible for the multidecadal variations in precipitation over the British Isles and north-western Europe.

Keywords Atlantic multidecadal variability · Summer . Europe $\cdot$ Linear baroclinic response

\section{Introduction}

The Atlantic multidecadal variability (AMV) has a profound impact on European summer climate (Sutton and Hodson 2005; Knight et al. 2006). Substantial increase of temperature in central Europe is observed during a strong phase of the AMV (Sutton and Hodson 2005). The AMVrelated atmospheric pathway to the European summer climate, however, is still not understood. Previous studies considered the summer North Atlantic Oscillation [SNAO, Folland et al. (2009)] and associated meridional shifts in the storm tracks explaining variations of the European summer climate (Dong et al. 2012; Bladé et al. 2012). Even though a direct link of the AMV to the SNAO is still controversial. In addition to the summer North Atlantic Oscillation (SNAO), an alternative atmospheric response could be the baroclinic atmospheric response to shallow diabatic heating anomalies in the extra-tropics (Smagorinsky 1953; Hoskins and Karoly 1981; Kushnir 1994). Such diabatic heating can result from AMV-related surface heat fluxes as recently shown in the analysis of observations (Gulev et al. 2013). Here, we investigate the atmospheric response to such diabatic heating in the North Atlantic and we identify a remote pathway which explains the observed multidecadal variations of European summer climate. 
The central to eastern (C-E) European summer climate exhibits prominent multidecadal variations as shown by surface air temperature (SAT) in Fig. 1a. For example, there is a likelihood of appearance of high SATs between 1930 and 1960, and from 1990 onwards, and low SATs between 1960 and 1990. Similar multidecadal variations, however, have also been observed for other parameters, for example for the precipitation over the British Isles and north-western European (BE) region (Fig. 1b), suggesting that BE precipitation and C-E European SATs stem from the same dynamical response at multidecadal time scales.

Multidecadal variations of C-E European SATs and multidecadal variations of North Atlantic sea surface temperatures (SSTs), the AMV, have similar temporal variations with a correlation of 0.84 (Fig. 1a). Previous studies suggested that the AMV affects European summer climate (e.g. Sutton and Hodson 2005; Sutton and Dong 2012; Robson et al. 2012; Müller et al. 2014). The observed differences between the warm phase (1931-1960) and the cold phase (1961-1990) of the AMV have shown warmer summer SATs over C-E Europe to be associated with a warm phase of the AMV and vice versa (Sutton and Hodson 2005; Sutton and Dong 2012). Similar results are found for the transition from a cold phase to a warm phase in the 1920s (Müller et al. 2014) and the transition from a warm phase to a cold phase in the 1960s during the North Atlantic cooling (Sutton and Dong 2012; Robson et al. 2012). These studies also showed, during the warm phase of AMV, a positive summer precipitation anomaly over northern Europe including the BE region, thus suggesting a close association between the multidecadal variations of $\mathrm{C}-\mathrm{E}$ European SATs and BE precipitation in summer. In summary, the AMV is accepted as a governing factor for multidecadal variations of European summer climate. However, a mechanism describing the atmospheric pathway from the AMV to European summer climate has yet to be established.

The principal mode of interannual variability in summer sea-level pressure (SLP) over the North Atlantic-European (NAE) region is usually referred to as SNAO which has a typical North-South dipole-like structure in SLP with the southern lobe over the north-western Europe. Vertically, the SNAO is near equivalent barotropic in structure and on interannual time scales, it has significant impact on the climate over the north-western Europe by varying the position of the North Atlantic storm track (Folland et al. 2009; Dong et al. 2012; Bladé et al. 2012). Additionally, Bladé et al. (2012) found the influence of SNAO on Mediterranean climate in interannual as well as multidecadal time scales. However, SNAO and AMV are not found to be significantly related on multidecadal time scales. Moreover, on multidecadal time scales to our knowledge no previous research identified any robust relation of the SNAO with C-E European SATs and BE precipitation. Therefore, the AMV-related multidecadal variations of $\mathrm{C}-\mathrm{E}$ European SAT are unlikely to be due to an SNAO type of atmospheric response.

An alternative mechanism to the SNAO is the baroclinic atmospheric response related to the extra-tropical SST anomalies (Hoskins and Karoly 1981; Kushnir 1994;
Fig. 1 a Time series of averaged central to eastern (C-E) European $\left(40^{\circ} \mathrm{N}-55^{\circ} \mathrm{N}\right.$, $\left.10^{\circ} \mathrm{E}-30^{\circ} \mathrm{E}\right)$ summer Surface Air Temperature (SAT) with 11 years running mean from 20CRv2 (black), from CRU TS3.2 (blue) and SST over the region $35^{\circ} \mathrm{N}-50^{\circ} \mathrm{N}$ and $7.5^{\circ} \mathrm{W}-75^{\circ} \mathrm{W}$ (red) for the summer (JJA) months from 20CRv2 (Compo et al. 2011) (units in $\left.{ }^{\circ} \mathrm{C}\right)$. b Time series of averaged British Isles and north-western European (BE) $\left(50^{\circ} \mathrm{N}-60^{\circ} \mathrm{N}\right.$, $0^{\circ} \mathrm{E}-15^{\circ} \mathrm{E}$ ) region summer precipitation with 11 years running mean from 20CRv2 (black), from CRU TS3.2 (blue) (units in $\mathrm{mm} \mathrm{day}^{-1}$ ) and C-E European SAT with 11 years running mean (red) for the summer (JJA) months from 20CRv2 (Compo et al. 2011) (units in $\left.{ }^{\circ} \mathrm{C}\right)$
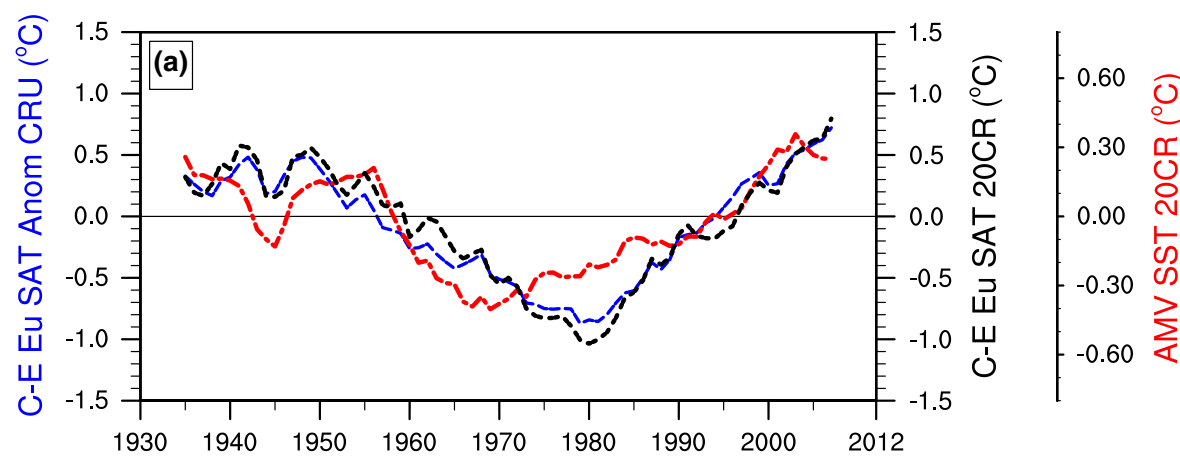

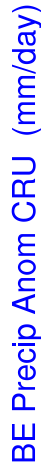

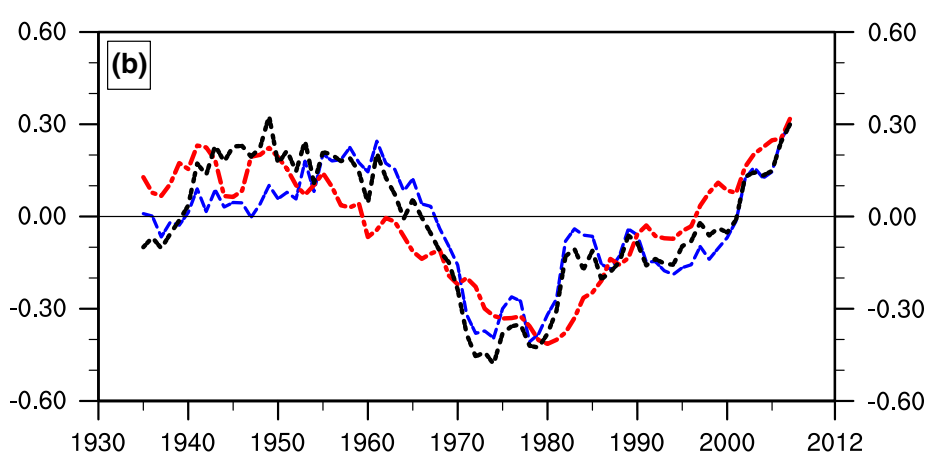

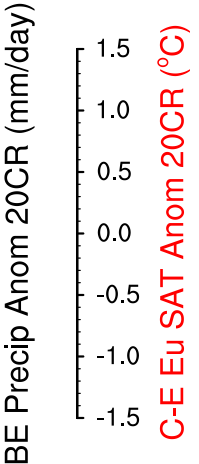


Kushnir and Held 1996). According to the linear quasigeostrophic theory, in the extra-tropical ocean, a shallow diabatic heating induces a surface low east of the centre of heating. The surface low deviates the colder polar wind towards the heating region and drives sub-tropical warmer air to the east of the centre of the low pressure (Hoskins and Karoly 1981). Kushnir (1994) found a similar pressure response for interdecadal variations of the SST in the extra-tropical Atlantic Ocean over all seasons. From that he inferred that the atmospheric response to SSTs over the North Atlantic sector differs between interannual and interdecadal time scales. Similar results were found in an atmospheric general circulation model experiment by prescribing the SST anomalies over the extra-tropical Atlantic Ocean (Kushnir and Held 1996). Moreover, Gulev et al. (2013) showed that the surface heat flux over the north western Atlantic region shows similar multidecadal variations as the AMV and thus may produce the diabatic heating background required for such a baroclinic response. In addition, Gastineau and Frankignoul (2015) recently showed that such heating during summer is shallow in nature. These results strongly suggest an investigation of a linear baroclinic response to diabatic heating and its impact on the multidecadal variations of C-E European SAT.

Previous studies emphasize on limitations of such baroclinic response to diabatic heating under the influence of transient eddies (Kushnir et al. 2002). The transient eddies can change the baroclinic nature of the response to equivalent barotropic, which indeed is the case in winter (Czaja and Frankignoul 2002). However, the strength of the transient eddy forcing depends on the climatological mean state of the season (Peng and Whitaker 1999). Therefore, it could be possible that the eddy forcing in summer is not as strong as winter which we must ensure to confirm the linear baroclinic response to extra-tropical heating.

We use the National Center for Environmental Prediction (NCEP) Twentieth Century Reanalysis Project version 2 (20CRv2) data (Compo et al. 2011) to asses the nature of multidecadal variations in the C-E European summer SAT and to establish an atmospheric pathway from the AMV to the C-E European SAT. Similarly, we show a plausible cause of multidecadal variations for the BE precipitation as a manifestation of the same dynamical mechanism. The description of the data used and the methods applied can be found in Sect. 2. The nature of the multidecadal variations of European summer temperature and its relation with the north-western Atlantic heat flux are explained in Sect. 3. Section 4 describes the observed North-AtlanticEuropean East West (NEW) mode during summer and its association with the C-E European summer temperature variations. The probable mechanisms for the association of the NEW mode with European climate are explained in Sect. 5. Section 6 adds some discussion regarding the new findings and Sect. 7 summarizes the major results found in this study.

\section{Data and methods}

Here, we use the 20CRv2 data as a proxy for observations (Compo et al. 2011). The data are based on the experimental version of the NCEP Global Forecast System model, whose setup we briefly describe here. The observed variables were derived using synoptic surface pressure data records from the International Surface Pressure Databank (ISPD). The monthly observed SST and sea ice concentration data from HadISST 1.1 were used as boundary condition during the simulations (Rayner et al. 2003). The reanalysis fields were generated for 6 hourly temporal and $2^{\circ}$ horizontal resolution on 24 vertical levels. A 'deterministic' type Ensemble Kalman Filter algorithm was used for the assimilation (Whitaker et al. 2004; Compo et al. 2006). An ensemble of 6-hourly global fields was performed for the entire period of the simulation. Here, we use for our analysis the monthly mean fields derived from the 6-hourly fields covering the period 1930-2012. For further verification, we use the SAT and precipitation data, stem from the CRU TS3.2 and covering the period $1930-2012$ with $0.5^{\circ}$ resolution (Harris et al. 2014). For reasons explained in Sect. 3.2, we restrict our analysis to the time period between 1930 and 2012 in 20CRv2.

To analyse the governing factors behind the multidecadal variations of the European summer climate, we apply for all variables a 11 years running mean to the detrended time series of seasonal [June-July-August (JJA)] means. We remove the trend by a linear fit. Composites of the respective variables are constructed on the basis of a predefined index such as the AMV or the SAT index over a certain region. The composites of the corresponding parameters are defined as the difference of the epochs above and below zero line of the reference index. The significance of the composites is tested using a bootstrap algorithm where the composite at each grid point is calculated on the basis of permutation of the reference index for 1000 times where a block of 11 years is permuted to consider the effect of smoothing (11 years running mean) in the data. If the 975 out of the 1000 composite values at any grid point is greater or less than the actual composite value, then according to a two-tailed test that grid point is considered significant at $95 \%$ level (Matthews and Kiladis 1999; Schreck et al. 2013).

For defining the relevant period considered in this study (1930-2012), we perform running correlation between two reference indexes (AMV and Heat Flux) using a 70 years time window. The significance of the running correlation is calculated through permutation of the indexes for 1000 
times and forming a null distribution on the basis of the highest correlation found in each attempt. We permute a block of 11 years to account for the auto-correlation in the time series due to smoothing.

In case of Pearson's correlation coefficient values mentioned in the paper, for the period 1930-2012, any correlation value above $0.75(0.66)$ is significant at $95 \%(90 \%)$ level according to a two-sided student $t$ test with an equivalent sample size of 7 which accounts for the auto-correlation in the data due to smoothing. Similarly, for the entire period of 20CRv2 (1871-2012) the $95 \%$ significance level of correlation is 0.58 with equivalent sample size of 12 .

To find the principle mode of variations in a parameter, the empirical orthogonal functions (EOF) of the spatial variations are calculated from the parameters by using their anomaly covariance matrix (North et al. 1982). This procedure is also known as principal component analysis (PCA). The robustness of the orthogonal modes is checked by rotating the EOFs using Kaiser row normalization and the varimax criterion (Mestas-Nunez 2000). The coupled mode of variations between two parameters are further calculated using the singular value decomposition (SVD) technique on their covariance matrix (Bretherton et al. 1992).

For understanding the role of the synoptic eddies, the transient component of the velocity and temperature fields are calculated using a 2-6 day band pass Lanczos filter on the field of daily data over a particular season (Duchon 1979).

For deriving the blocking frequency, the blocking index is used in its extension to two dimensions (Scherrer et al. 2006). The daily $500 \mathrm{hPa}$ geopotential height (Z500) data from 20CRv2 are used to construct the blocking index. For the two dimensional extension of the index, all grid latitudes between $35^{\circ} \mathrm{N}-75^{\circ} \mathrm{N}$ are accounted as central latitudes. A latitude gradient of $15^{\circ}$ north and south is taken around every central latitude to calculate the Z500 gradient. A grid point is considered as blocked if the northern Z500 gradient is less than $-10 \mathrm{~m}$ and southern Z500 gradient is more than $0 \mathrm{~m}$ for minimum 5 consecutive days.

\section{Multidecadal variations of European summer SAT}

\subsection{Central to Eastern European SAT Index}

We first define the C-E European SAT index, using the first mode of the principal component analysis of summer (JJA) 2 meter air temperature (11 years running mean) over the region $35^{\circ} \mathrm{N}-75^{\circ} \mathrm{N}$ and $20^{\circ} \mathrm{W}-50^{\circ} \mathrm{E}$ (Fig. 2a). The spatial distribution of the first mode covers much of the central to eastern $(\mathrm{C}-\mathrm{E})$ European area and its time series shows
Fig. 2 a The EOF1 of the summer (JJA) $2 \mathrm{~m}$ air temperature in ${ }^{\circ} \mathrm{C}$ (11 years running mean) for the time period 1930-2012. The explained variance is $63 \%$. b First principal component (PC1) of EOF SAT (black) with AMV index (red) which is constructed on the basis of the averaged SST (in ${ }^{\circ} \mathrm{C}$ ) over the region $35^{\circ} \mathrm{N}-50^{\circ} \mathrm{N}$ and $7.5^{\circ} \mathrm{W}-75^{\circ} \mathrm{W}$
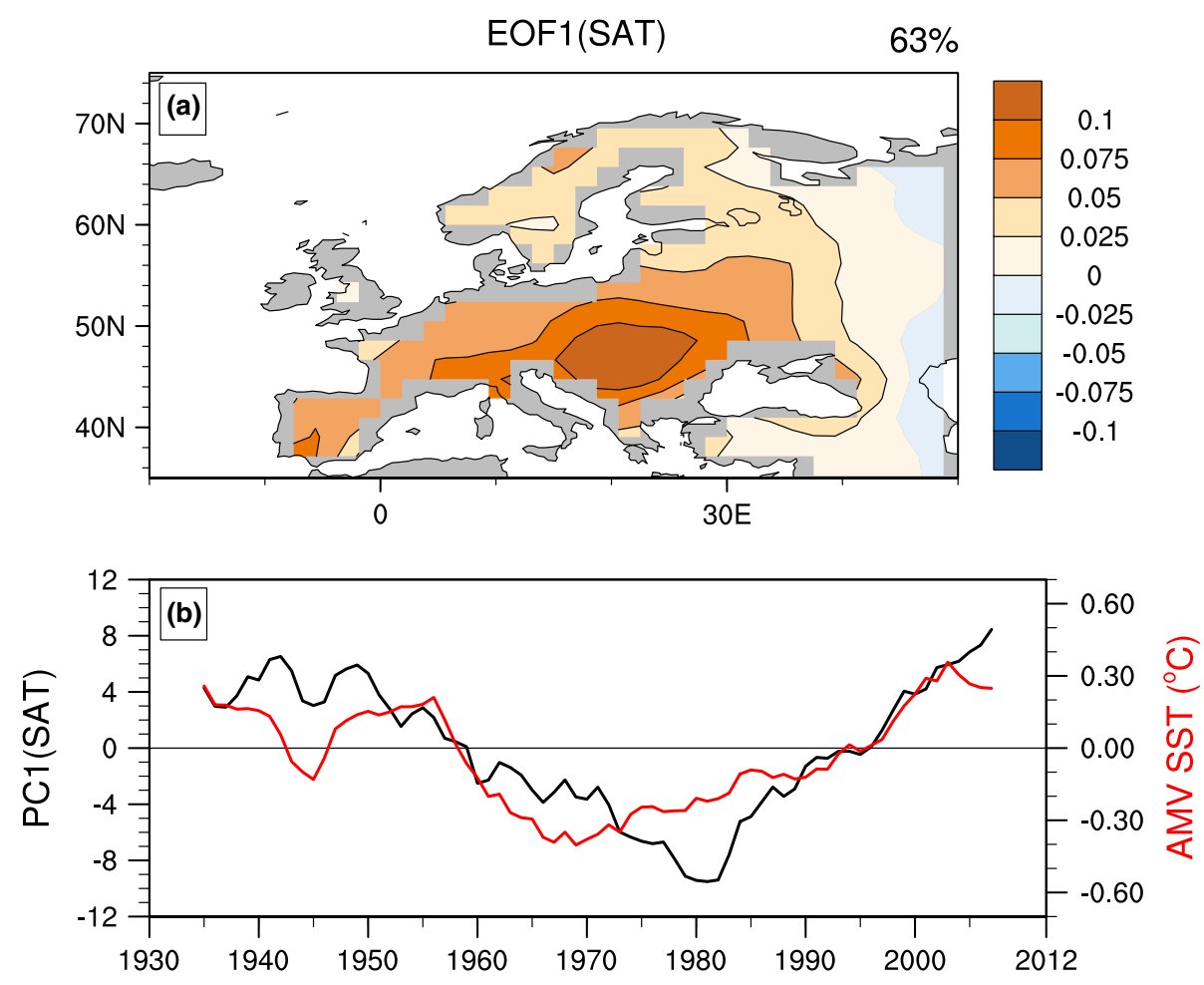
strong multidecadal variations. This mode explains $63 \%$ of the total variability. The temporal variations of this mode are similar to the AMV (Fig. 2b) (temporal correlation $=0.82$ ) and thus indicate the close correspondence of the C-E European temperature in summer with the North Atlantic SST variations.

\subsection{Relation between European summer SAT and North Atlantic heat flux}

Before considering the atmospheric pathways, we investigate the nature of the relation between the North Atlantic surface (sensible + latent) heat fluxes and the AMV in 20CRv2 for the entire period (1871-2012). A composite of the heat flux based on the AMV index identifies the region of the most intensified heat fluxes at the central subpolar gyre region and eastern subtropical Atlantic and shows
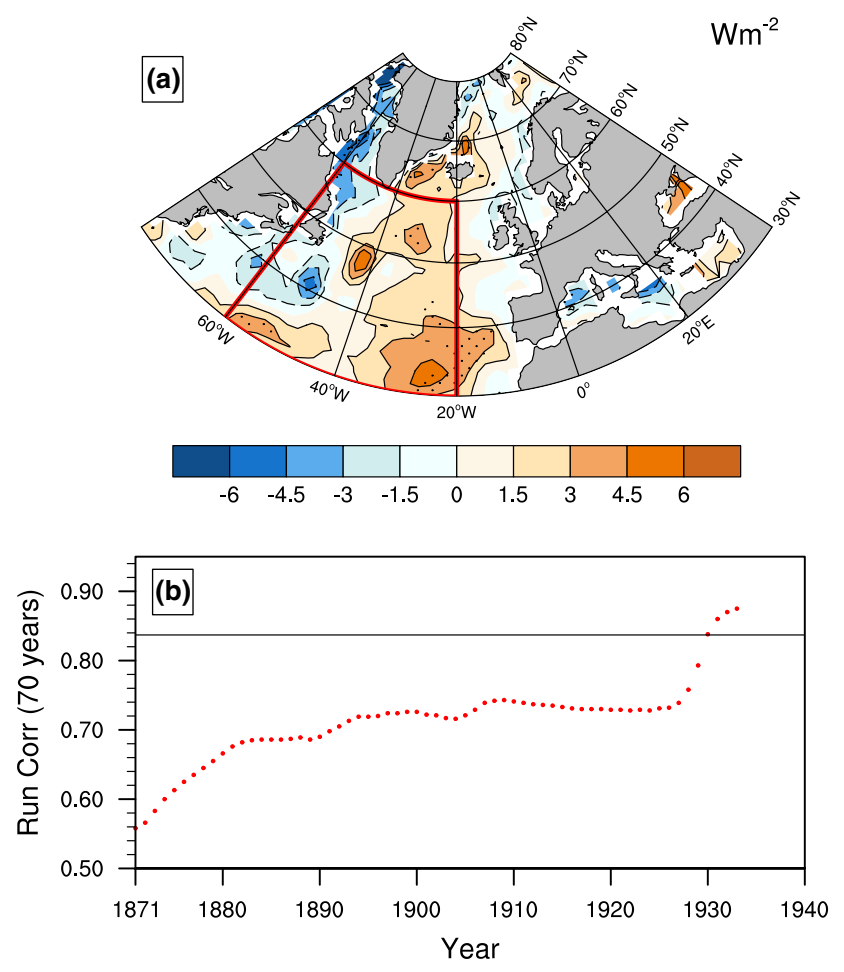

Fig. 3 a Composite of total (sensible + latent) surface heat flux anomaly (11 years running mean) in $\mathrm{Wm}^{-2}$ over the ocean with respect to the positive-negative phase of the AMV index (18712012). Positive values denote that the ocean is releasing heat to the atmosphere. The dotted regions denote areas with significance at $95 \%$ level based on block-bootstrap test. The red box is the area considered for constructing averaged heat flux anomaly over the northwest Atlantic. Only the significant grid points inside the red box are taken for making the average. b Running correlation of AMV index and the averaged heat flux (both 11 years running mean) for 70 years windows. The value of the correlation is plotted as red dots at the starting point of the correlation window. The horizontal black line is showing the $95 \%$ significance level of the running correlation based on block-bootstrap test mostly positive heat fluxes over the North Atlantic except over the western Atlantic and Labrador Sea (Fig. 3a). This spatial pattern is similar to the findings of Gulev et al. (2013), who use observations. Next, we use an average of all heat flux anomalies that are significant at $95 \%$ level over the north-western Atlantic Ocean to relate the heat flux anomalies to the AMV. The evolution of a 70 years time window running correlation is shown in Fig. 3b. The overall correlation between the AMV and heat flux is 0.69 , which is mainly due to stronger relation in the later part of the record. The values of the running correlation are low and not significant at the beginning of the record. Only from 1930 onward, the correlations are above the significance level of $95 \%$ (0.837). One reason for the temporally changing relation between the AMV and heat flux could be the limited number of observations assimilated at the beginning of the 20CRv2 compared to the later periods (Krueger et al. 2013; Gastineau and Frankignoul 2015). Since the diabatic heating of the north-western Atlantic Ocean is the foundation of our proposed atmospheric response generated from AMV, the significant relation between these two parameters is essential. Hence, we restrict our entire analysis to the period from 1930 onwards from 20CRv2.

Given the close relation of C-E European SAT and the AMV, composites of the surface heat flux with respect to the C-E European SAT index shows a similar response as for the AMV (Fig. 4). The heat flux composite shows an area in the north-western Atlantic which is significantly and

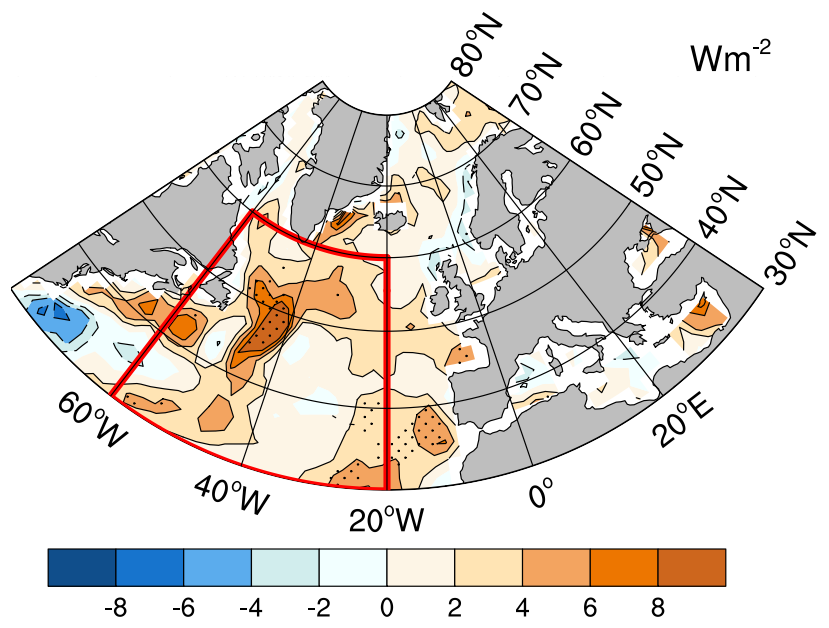

Fig. 4 Composite of total (sensible + latent) summer surface heat flux anomaly (11 years running mean) in $\mathrm{Wm}^{-2}$ over the ocean (color) with respect to the positive-negative phase of the C-E European SAT Index (1930-2012). Positive values denote that the ocean is releasing heat to the atmosphere. The dotted regions denote areas significant at $95 \%$ level based on block-bootstrap test. The red box is the area considered for constructing averaged heat flux anomaly over north-west Atlantic Ocean. Only the significant grid points inside the red box are taken for making the average 
Fig. 5 Time series of heat flux anomaly in $\mathrm{Wm}^{-2}$ (average of significant grid points within the red box in Fig. 3) (blue), Surface Air Temperature (SAT) index (PC1 SAT from Fig. 1b) with 11 years running mean (black), and AMV SST (red) in ${ }^{\circ} \mathrm{C}$ for the summer (JJA) months

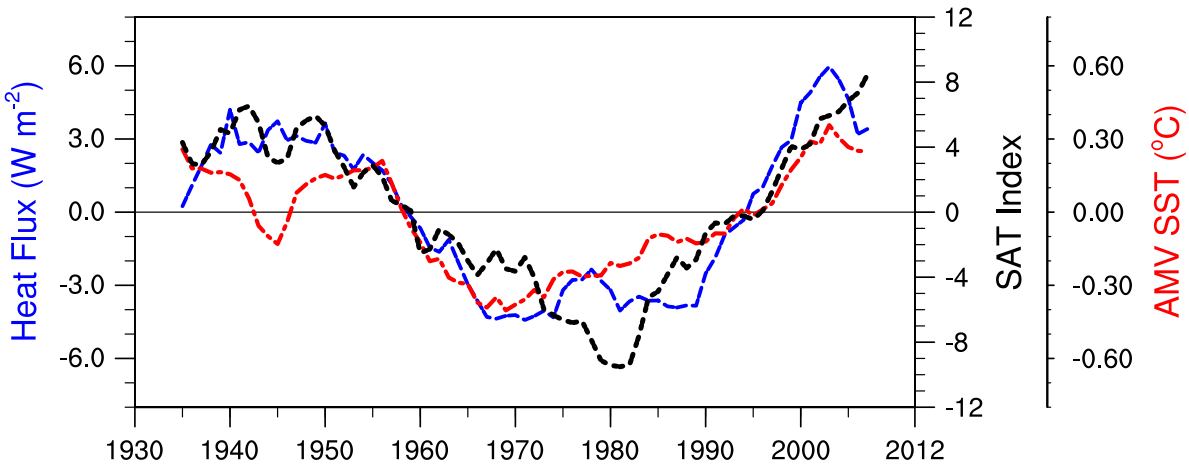

positively related to the C-E European SAT. The averaged surface heat flux over this region is of the order $\sim 6 \mathrm{~W} \mathrm{~m}^{-2}$. Vertically, the warming is maximum within $\sim 700 \mathrm{hPa}$ (not shown) which is in accordance to previous studies (Kushnir et al. 2002; Gastineau and Frankignoul 2015). Hence, considering the depth of the heating as up to $700 \mathrm{hPa}$ $(\sim 2-3 \mathrm{~km})$ the heating rate would be of magnitude $\sim 0.1$ to $0.2 \mathrm{~K} \mathrm{day}^{-1}$. Apart from that, the eastern subtropical gyre also provides some heat to the atmosphere.

The temporal variations of the heat flux anomaly over the north-western Atlantic region $\left(30^{\circ} \mathrm{N}-60^{\circ} \mathrm{N}\right.$, $20^{\circ} \mathrm{W}-60^{\circ} \mathrm{W}$ ), the variations of the SAT index and the AMV index, all show similar multidecadal variations over the last century (Fig. 5). Here, only the grid points showing significance at $95 \%$ level with respect to SAT index are considered when calculating the average of the heat flux anomaly over the above mentioned area. The averaged heat flux anomaly has a temporal correlation with the SAT index of 0.89. The close association of the C-E European SAT with the north-western Atlantic heat flux provides the basis to examine the dynamical atmospheric response in 20CRv2, which can eventually affect the European summer climate at multidecadal time scales.

\section{NEW mode: a linear baroclinic response}

In a conceptual framework, Hoskins and Karoly (1981) examined the atmospheric response to extra-tropical diabatic heating within a baroclinic model. In particular they showed that a shallow diabatic heating forces a negative surface pressure anomaly east of the centre of the heating. The composite of the 20CRv2 SLP anomalies (11 years running mean) during summer (JJA) shows a low pressure anomaly situated over the north-eastern Atlantic region and an east-west wave-like response further downstream (Fig. 6). The low pressure anomaly over the North Atlantic exceeds $1 \mathrm{hPa}$ at the centre of the system and is located eastward of the positive heat flux (Fig. 4). This SLP anomaly is associated to SST anomaly of $\sim 1 \mathrm{~K}$ which is consistent with the study of Kushnir (1994). The subsequent high pressure anomaly is built over the central to north-eastern European region. The high pressure anomaly is followed by low and high pressure anomalies with downstream decreasing intensity. This wave-like response could be the result of a baroclinic response to the diabatic heating in the mid-latitudinal Atlantic Ocean (Kushnir 1994).

The formation of the low pressure anomaly at the east of the mid-latitudinal heating is also in accordance with the framework of the linear quasi-geostrophic (QG) theory. According to that theory, the surface low balances the excess heating by driving colder sub-polar winds towards the extra-tropical heat source through horizontal temperature advection (Hoskins and Karoly 1981). As a result of the formation of this low pressure anomaly, the warmer sub-tropical air would also be driven towards the extratropics at the east of the center of the low pressure anomaly. This advection of warmer air is suggested to lead (at least partially) to the warming of the European region at multidecadal time scales; situated just east of the center of the low pressure (Fig. 6). The findings from the analysis of the composite of the heat flux (Fig. 4) and of the SLP (Fig. 6) suggest that the diabatic heating at the surface of northwestern Atlantic Ocean leads to the development of the low pressure anomaly and the subsequent wave-like response downstream as a linear baroclinic response.

Before continuing with the QG framework, we show the east-west wave-like SLP response is the primary mode of variations on multidecadal time scales. Previous studies showed that the SNAO plays a major role over the extratropical Atlantic region from interannual time scales to inter decadal time scales (e.g. Folland et al. 2009; Bladé et al. 2012). However, in contrast to the north-south SNAO SLP structures, the composites of SLP with respect to the C-E European SAT index (Fig. 6) reveals an east-west wave-like structure over the NAE region. To examine the differences of the east-west wave-like SLP response from the SNAO, an EOF analysis is performed for SLP over the domain $40^{\circ} \mathrm{N}-80^{\circ} \mathrm{N}$ and $60^{\circ} \mathrm{W}-100^{\circ} \mathrm{E}$ (Fig. 7). The principal mode shows the east-west wave-like response in SLP 


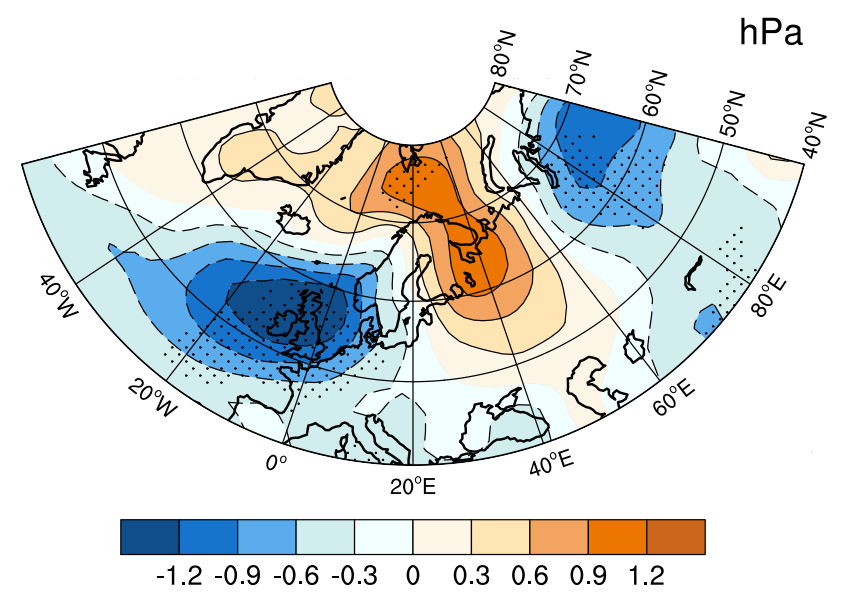

Fig. 6 Composite of 11 years running mean SLP in summer (JJA) in $\mathrm{hPa}$ with respect to the positive-negative phase of the C-E European SAT index. The dotted regions denote areas with significance at $95 \%$ level based on block-bootstrap test

similar to the SLP composites in Fig. 6 (Fig. 7a). The time series of the principal mode explains $36 \%$ of the total variance and exhibits multidecadal variations with negative values from 1960-1990 and positive values before 1960 and after 1990 (Fig. 7b). Based on the spatial location, we name the principle mode as North-Atlantic-European East West (NEW) mode. The correlation of the C-E European SAT index with the time series of the principal component of the NEW mode is significant $(r=0.85)$. This analysis confirms that the first mode of SLP is associated to the multidecadal variations in the $\mathrm{C}-\mathrm{E}$ European SAT. The second mode (Fig. 7c) shows the characteristic north-south SLP structure of the SNAO in its negative phase, and explains $29 \%$ of the total variability. The temporal variations of the second mode (Fig. 7d) is similar to Folland et al. (2009) and has no substantial relation with the multidecadal variations of $\mathrm{C}-\mathrm{E}$ European SAT $(r=-0.07)$. The same results are found after rotating the EOFs (not shown). Therefore, these two modes are robust over the NAE region.

We perform a SVD of geopotential height in vertical with respect to SLP to understand the vertical structure of the two multidecadal modes (NEW and SNAO) (Fig. 8). Figure 8b, e show the heterogeneous pressurelongitude cross-section correlation maps of geopotential height over the NAE region averaged from $50^{\circ} \mathrm{N}$ to $60^{\circ} \mathrm{N}$. The corresponding homogeneous SLP modes are shown in Fig. 8a, d. While considering the vertical structure, the first mode of SLP co-variability becomes the SNAO mode which explains $46 \%$ of the co-variance over this region. The second mode reveals the NEW mode which
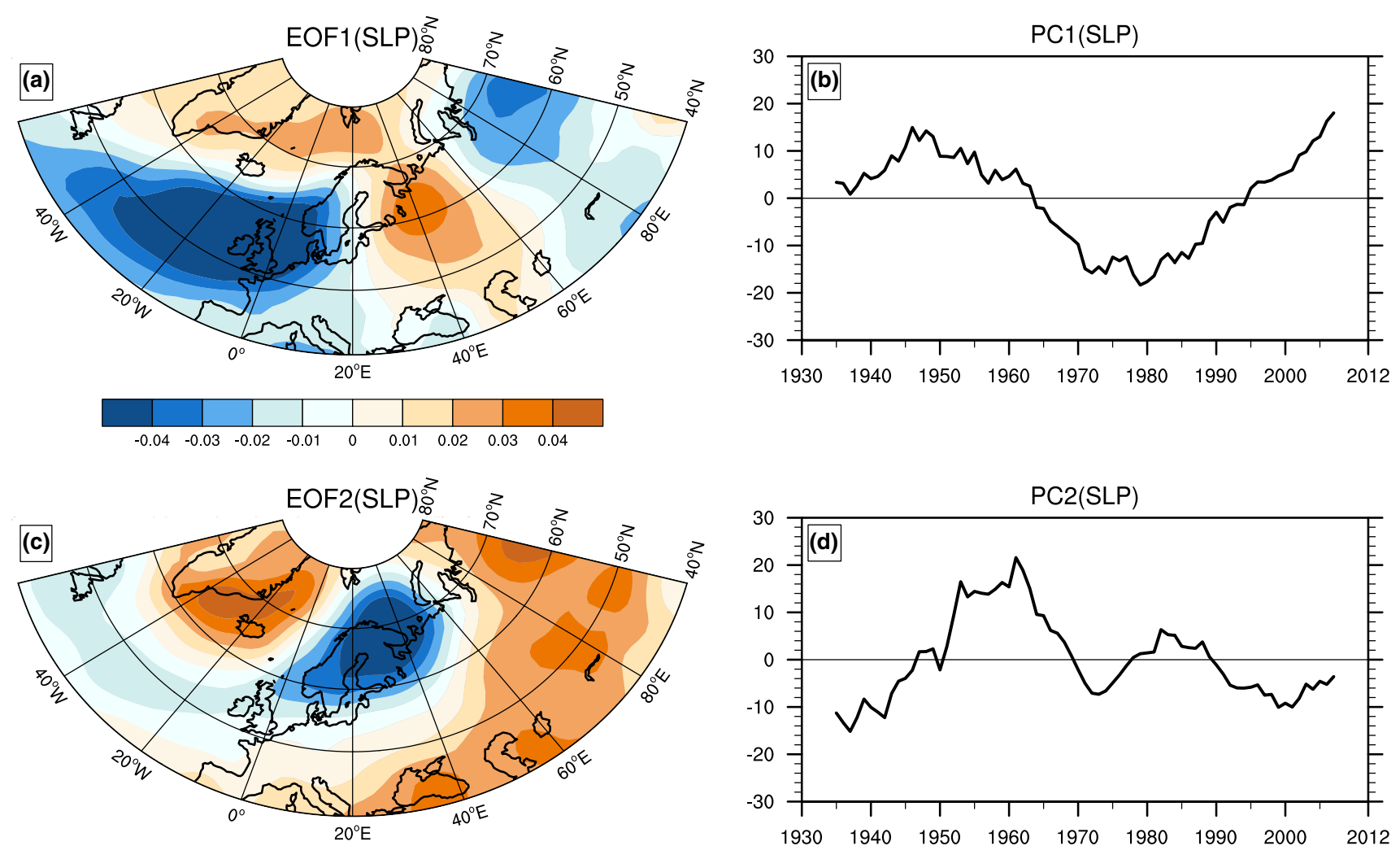

Fig. 7 a EOF1 and c EOF2 of SLP in summer (11 years running mean) in hPa over the region shown in the figure for the period 1930-2012. EOF1 and EOF2 explain 36 and $29 \%$ of the total variance respectively. b, $\mathbf{d}$ are the corresponding PC1 and PC2 of the EOFs 

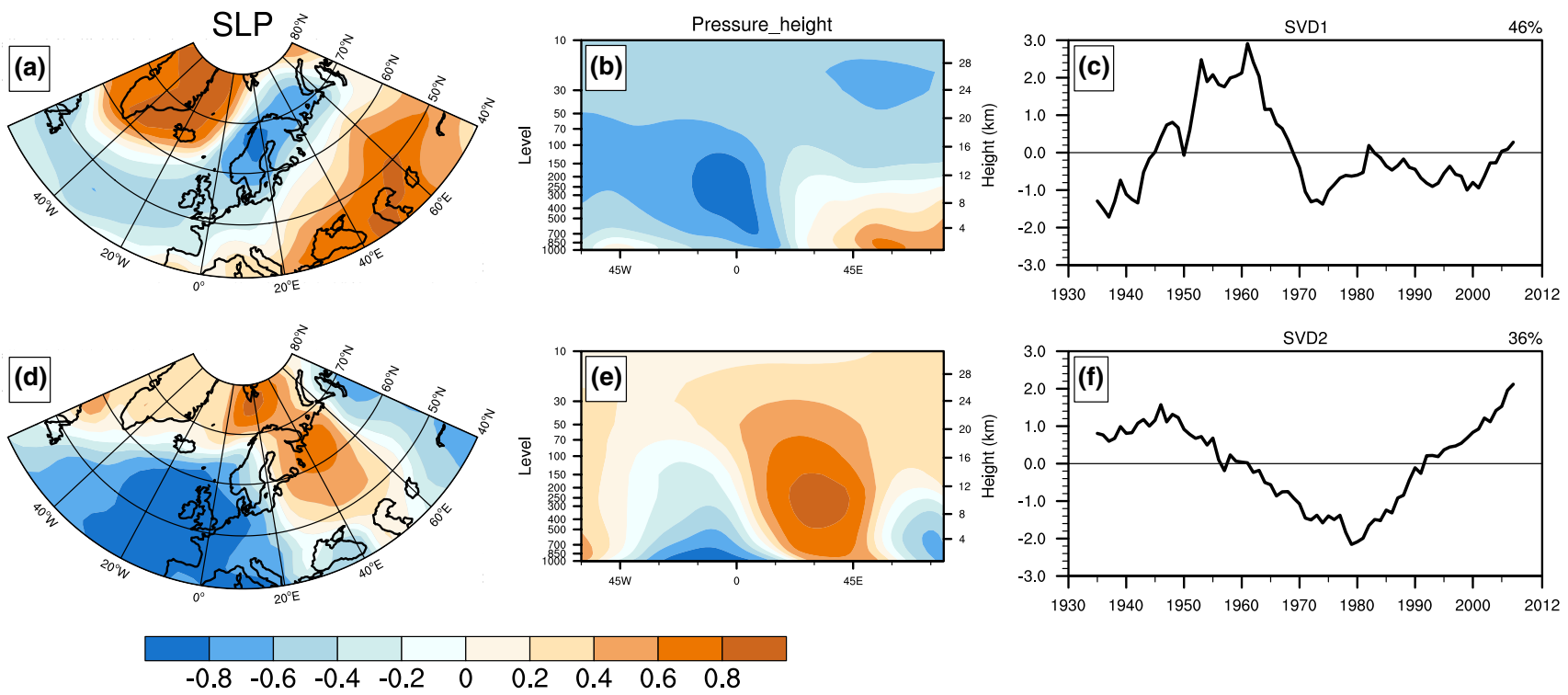

Fig. 8 SVD1 of a SLP with b pressure-longitude cross-section of geopotential height (11 years running mean) and SVD2 of d SLP with e pressure-longitude cross-section of geopotential height in summer (11 years running mean) over the respective regions for the period 1930-2012. The pressure-longitude cross-section of geopoten-

explains $36 \%$ of the co-variance. The equivalent barotropic structure of the SNAO mode kept the footprint of this mode on upper levels of the atmosphere and hence, the SNAO mode becomes the principle mode of co-variance. For the NEW mode, the low pressure anomaly at the surface over the north-eastern Atlantic is still present at $500 \mathrm{hPa}$ but it diminishes considerably in magnitude from its strength at the surface which is an indication of a linear baroclinic-like response to midlatitude surface heating (Kushnir and Held 1996). Moreover, due to the baroclinic-like nature of this mode, it has weaker covariance in the upper atmospheric levels than SNAO mode and hence it becomes the 2nd mode of co-variance. Another interesting feature of the NEW mode is the downstream high-pressure anomaly which is enhanced considerably in magnitude in the mid atmospheric levels and it is surrounded by the two low pressure anomalies. The composite with respect to C-E European SAT Index resembles the same vertical structure (not shown). This vertical structure is indicating a blocking-like condition related to the NEW mode. We further discuss about this blocking-like feature while finding the impact of the NEW mode on European climate.

The previous studies suggest that in presence of a strong non-linear transient eddy forcing the direct linear response to surface heating can change largely from a baroclinic low pressure anomaly downstream to an equivalent barotropic high through a secondary circulation (Kushnir et al. 2002). The transient eddy forcing to the mean flow explains tial height is the average of the latitude extent $50^{\circ} \mathrm{N}-60^{\circ} \mathrm{N}$. SVD1 and SVD2 explain 46 and $36 \%$ of the total covariance respectively and the spatial patterns represent the correlation maps. $\mathbf{c}$ and $\mathbf{f}$ are the corresponding PC1 and PC2 of the SVDs representing the time series of the normalized expansion coefficients

why the atmospheric response in winter is mainly barotropic (Czaja and Frankignoul 2002). However, the forcing also depends on the climatological mean flow of the season (Peng and Whitaker 1999). Hence, to confirm that the NEW mode is in accordance to the linear QG theory, we should get a negligible influence from the transient eddies in summer compared to winter.

The transient eddies affect the mean flow through eddyheat flux and eddy-momentum flux. The eddy-heat flux is denoted by $v^{\prime} T^{\prime}$ where $v^{\prime}$ and $T^{\prime}$ are the 2-6 day band pass filtered component of the meridional wind and temperature field. The lower tropospheric eddy heat flux combined with the Coriolis force creates a secondary circulation which accelerates the surface westerly flow where the $v^{\prime} T^{\prime}$ is maximum. Figure 9a shows the composite of the eddy-heat flux at $850 \mathrm{hPa}$ with respect to the time series of the leading EOF of multidecadal SLP variations in winter, the North Atlantic Ocsillation (NAO). The climatological mean eddyheat flux (in black contours) shows its strong presence in the mid-latitude and hence it strongly affects the mean westerly flow and the Euro-Atlantic climate in winter. The composite shows that the positive phase of the NAO is related to the enhancement of the eddy-heat flux and it mainly drives the westerly flow more northward which supports the results by Woollings et al. (2014b). In summer, however, the climatology of the transient eddy-heat flux is much weaker than winter (black contours in Fig. 9b). Moreover, the composite with respect to the NEW mode only shows eddy-heat flux with modest amplitude over the 

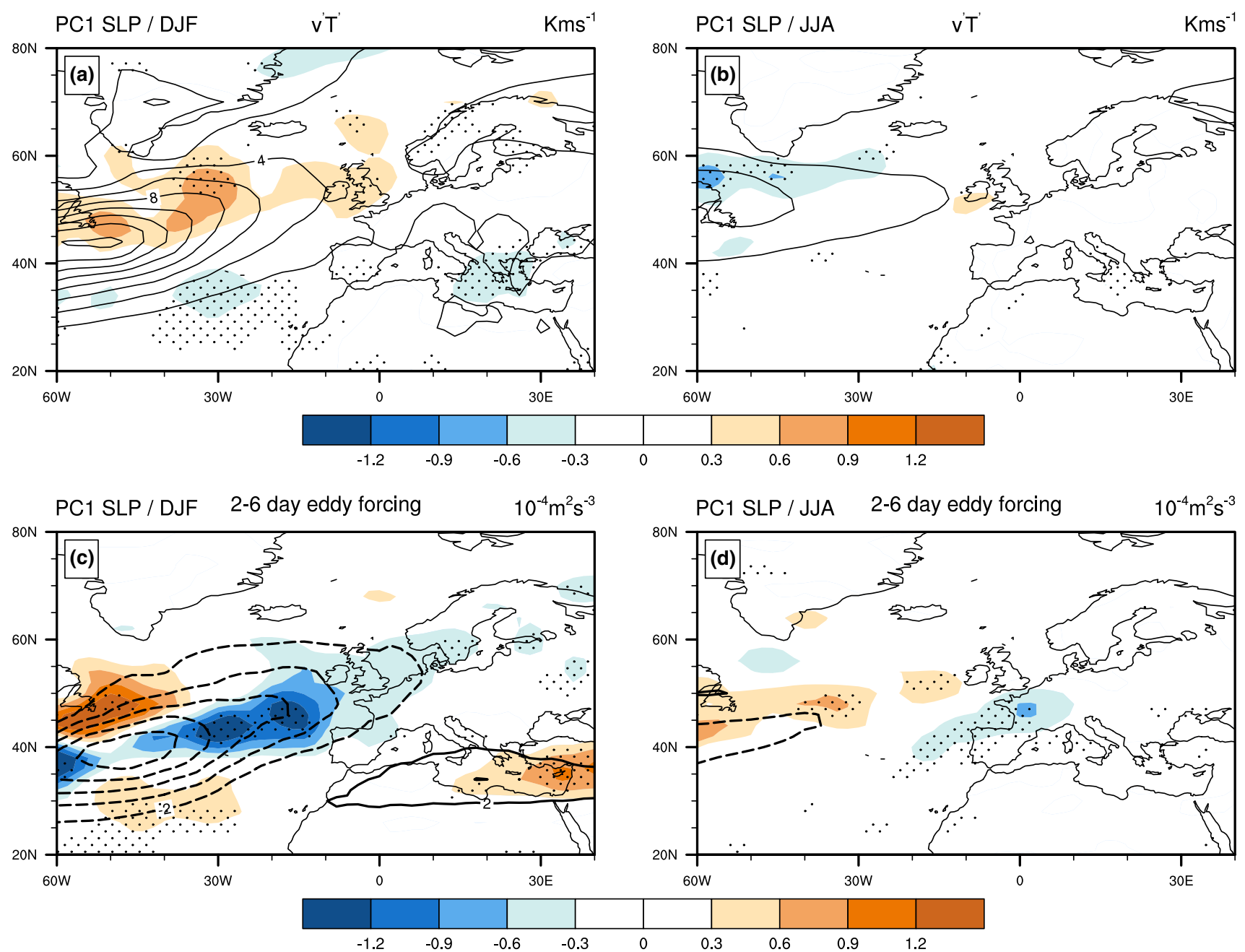

Fig. 9 a The composite of $2-6$ day $850 \mathrm{hPa} v^{\prime} T^{\prime}$ with respect to the PC1 of SLP EOF in winter (DJF, 11 years running mean). The EOF is constructed over the region $90^{\circ} \mathrm{W}-30^{\circ} \mathrm{E}$ and $30^{\circ} \mathrm{N}-90^{\circ} \mathrm{N}$ based on the study by Woollings et al. (2014a, b). The climatology is contoured from 4 to 10 with a spacing of $2 \mathrm{~km}^{-1}$. b Same as $a$ but the composites are with respect to the PC1 of SLP in summer from Fig. 7.

NAE region and it further weakens the climatology over the north-western Atlantic Ocean. Some negative values are seen north of the climatological mean. Over Europe, the magnitude is small and as we show in the next section, they are of an order smaller than the horizontal advection of heat. The same feature is seen in the composite with respect to C-E European SAT index (not shown).

We further investigated the role of eddy-momentum flux by calculating E.D from the study of Raible et al. (2010). $\mathbf{E}$ is the E-vector from Hoskins et al. (1983) with the vector components $\left(v^{\prime 2}-u^{\prime 2}\right) / 2$ and $-u^{\prime} v^{\prime}$ where $u^{\prime}$ and $v^{\prime}$ are the 2-6 day band pass filtered wind components. $\mathbf{D}$ is the deformation vector of the time mean flow with the components $\left(U_{x}-V_{y}\right)$ and $\left(V_{x}+U_{y}\right)$ where $U$ and $V$ are the seasonal mean wind components. The scalar product of the $\mathbf{E}$ c Same as $a$ but the composite of 2-6 day eddy-momentum forcing at $250 \mathrm{hPa}$ (E.D) in winter. Climatology is contoured from -10 to 10 with a spacing of $2 \mathrm{~m}^{2} \mathrm{~s}^{-3}$ and negatives contours are dashed. d Same as $b$ but for the composite of 2-6 day eddy-momentum forcing at $250 \mathrm{hPa}$ (E.D) in summer. The dotted regions denote areas with significance at $95 \%$ level based on block-bootstrap test

and $\mathbf{D}$ vector describes the exchange of the kinetic energy between the eddy and the mean flow (Mak and Cai 1989). Negative values of E.D denote that eddy is transferring kinetic energy to the mean flow and positive values denote the opposite. The climatology of E.D at 250 hpa in winter shows that over the North Atlantic, eddy prominently provides energy to the background mean flow (Fig. 9c). The composite of E.D in winter shows that at the positive phase of NAO, there is a strengthening of the eddy-momentum forcing east and west to the climatology and weakening in the north-south direction. However, in summer the strength of the climatological eddy-momentum forcing itself is much weaker than in winter. The composite with respect to the NEW mode shows further weakening of the climatology in summer through positive anomalies of E.D 
which indicates baroclinic production (Fig. 9d). However, over the western Europe, the composite shows rather weak but significant strengthening of eddy-momentum forcing. It could be a forcing from the baroclinic eddies associated with the downstream linear baroclinic response from the diabatic heating. Nevertheless, in absence of a strong climatological eddy forcing over this region, this localized eddy-momentum flux could not lead to resultant barotropic response. Presumably the same composite with respect to C-E European SAT index shows same feature (not shown).

In summary, these results suggest that at multidecadal time scales the east-west wave-like SLP response, which is related to the multidecadal variations of C-E European summer temperature, has a linear baroclinic signature, which is in turn distinctively different from the SNAO and the winter NAO.

\section{Impact of the NEW mode on European SAT}

Having identified the NEW mode as the atmospheric pathway from AMV to the multidecadal variations of European summer temperatures, we proceed to analyze how the NEW mode influences the variations of European summer climate. As shown by the composites and principal components, a positive heat flux is associated with a negative SLP anomaly, which includes temperature advection at its eastern part. To examine the horizontal temperature advection related to the multidecadal variations of the C-E European SAT, we consider the linearized quasigeostrophic thermal energy equation in steady state (e.g. Hoskins and Karoly 1981; Bader et al. 2013):

$\bar{u} \frac{\partial \theta^{\prime}}{\partial x}+v^{\prime} \frac{\partial \bar{\theta}}{\partial y}+\omega^{\prime} \frac{\partial \bar{\theta}}{\partial p}=\frac{Q}{C_{p}} \frac{\theta}{T}$

where $Q$ is the amount of heating, $C_{p}$ is the heat capacity in constant pressure, $\theta$ and $T$ are respectively the potential temperature and temperature at the surface of heating. $\bar{u}, \bar{\theta}$ represent the zonal mean of the zonal wind and potential temperature. The pressure is denoted by $p . \theta^{\prime}, v^{\prime}$ and $\omega^{\prime}$ are respectively the deviations of the potential temperature, meridional wind and vertical wind velocity from their zonal means. $\bar{u} \frac{\partial \theta^{\prime}}{\partial x}$ and $v^{\prime} \frac{\partial \bar{\theta}}{\partial y}$ are the zonal and meridional temperature advection terms. In this equation, we have assumed the transient eddy term to be small compared to the advective terms. Indeed a quantitative analysis for the preferred regions indicates that eddy heat flux is small compared to the major advection terms (Table 1). Further, $\omega^{\prime} \frac{\partial \bar{\theta}}{\partial p}$ is the vertical temperature advection which could also be negligible since its magnitude is much smaller than the horizontal temperature advcetion over the diabatic heating region
Table 1 The magnitude of the composite of zonal $\left(\bar{u} \frac{\partial \theta^{\prime}}{\partial x}\right)$, meridional $\left(v^{\prime} \frac{\partial \bar{\theta}}{\partial y}\right)$, vertical $\left(\omega^{\prime} \frac{\partial \bar{\theta}}{\partial p}\right)$ temperature advection terms from Eq. 1 and the advection of eddy heat flux $\left(\frac{\partial\left(v^{\prime} T^{\prime}\right)}{\partial y}\right)$ with respect to C-E European SAT index, averaged over the North-Western Atlantic diabatic heating region (a) $45^{\circ} \mathrm{N}-55^{\circ} \mathrm{N}, 40^{\circ} \mathrm{W}-50^{\circ} \mathrm{W}$ and over the $\mathrm{BE}$ region (b) $50^{\circ} \mathrm{N}-60^{\circ} \mathrm{N}, 0^{\circ} \mathrm{E}-15^{\circ} \mathrm{E}$ with units $\mathrm{K} \mathrm{day}^{-1}$ for summer. All terms are calculated at the level $850 \mathrm{hPa}$

\begin{tabular}{lllll}
\hline Region & $\bar{u} \frac{\partial \theta^{\prime}}{\partial x}$ & $v^{\prime} \frac{\partial \bar{\theta}}{\partial y}$ & $\omega^{\prime} \frac{\partial \bar{\theta}}{\partial p}$ & $\frac{\partial\left(v^{\prime} T^{\prime}\right)}{\partial y}$ \\
\hline (a) & 0.02 & 0.13 & 0.005 & 0.02 \\
(b) & 0.06 & 0.22 & 0.19 & 0.001 \\
\hline
\end{tabular}

(Table 1). $\frac{Q}{C_{p}} \frac{\theta}{T}$ is the diabatic heating term, where in the northern hemisphere, the $\frac{\partial \bar{\theta}}{\partial y}$ is negative as the meridional temperature gradient is negative, and $v^{\prime}$ should be negative to balance the diabatic heating $\frac{Q}{C_{p}} \frac{\theta}{T}$. Therefore, the subpolar colder wind should be driven towards the heating region. The way to advect this subpolar colder wind is through the formation of a low east of the heating. This low will drive the subpolar air towards the heating region (west of the center of the low pressure) due to formation of the low pressure.

\subsection{Temperature advection}

The composite of the $850 \mathrm{hPa}$ meridional temperature advection $\left(v^{\prime} \frac{\partial \bar{\theta}}{\partial y}\right.$ of Eq. 1) with respect to the C-E European SAT index is shown in Fig. 10a. Positive values denote northward advection. Keeping in mind that $\frac{\partial \bar{\theta}}{\partial y}$ is negative in the Northern Hemisphere, the diabatic heating term $\left(\frac{Q}{C_{p}} \frac{\theta}{T}\right)$ in Eq. 1 can be balanced only if $v^{\prime}$ is negative. Therefore the wind direction is from the pole towards the mid-latitudinal heating area resulting in a cold air advection. Over the north-western Atlantic region, indeed a south-ward temperature advection is identified. The area of this cold air advection coincides with the region of positive heat flux from the ocean. The meridional temperature advection over this region is of magnitude $\sim 0.1$ to $0.2 \mathrm{~K} \mathrm{day}^{-1}$ which is comparable to the diabatic heating rate over this region. Additionally, Table 1 shows the averaged magnitudes for composites of the advection terms from Eq. 1 and advection from transient eddy heat flux $\left(\frac{\partial\left(v^{\prime} T^{\prime}\right)}{\partial y}\right)$ over the diabatic heating region $\left(45^{\circ} \mathrm{N}-55^{\circ} \mathrm{N}, 40^{\circ} \mathrm{W}-50^{\circ} \mathrm{W}\right)$. The meridional temperature advection is clearly the dominant term compared to all the other advection terms. Hence, we can say that the cold air advection mainly provides the atmospheric counterpart to balance the diabatic heating; in accordance with the linearized quasigeostrophic thermal energy equation (Eq. 1).

We further identify a north-ward temperature advection centered over the British Isles and the North Sea, bringing moist air through advection of the subtropical warmer air. 
Fig. 10 Same as Fig. 6, but for a meridional temperature advection $v^{\prime} \frac{\partial \bar{\theta}}{\partial y}$ at $850 \mathrm{hPa}$, after Hoskins and Karoly (1981), where $v^{\prime}$ is the deviation of the meridional velocity from zonal mean and $\bar{\theta}$ is the zonal mean potential temperature and $\mathbf{b}$ the total precipitation. Units for the temperature advection is $\left[\mathrm{K} \mathrm{day}^{-1}\right]$ and for precipitation is $\left[\mathrm{mm} \mathrm{day}^{-1}\right]$. The dotted regions denote areas with significance at $95 \%$ level based on block-bootstrap test. c The time series of the precipitation anomaly (red) and the meridional temperature advection anomaly (blue) averaged over the region shown by a red box in Fig. 7a, b
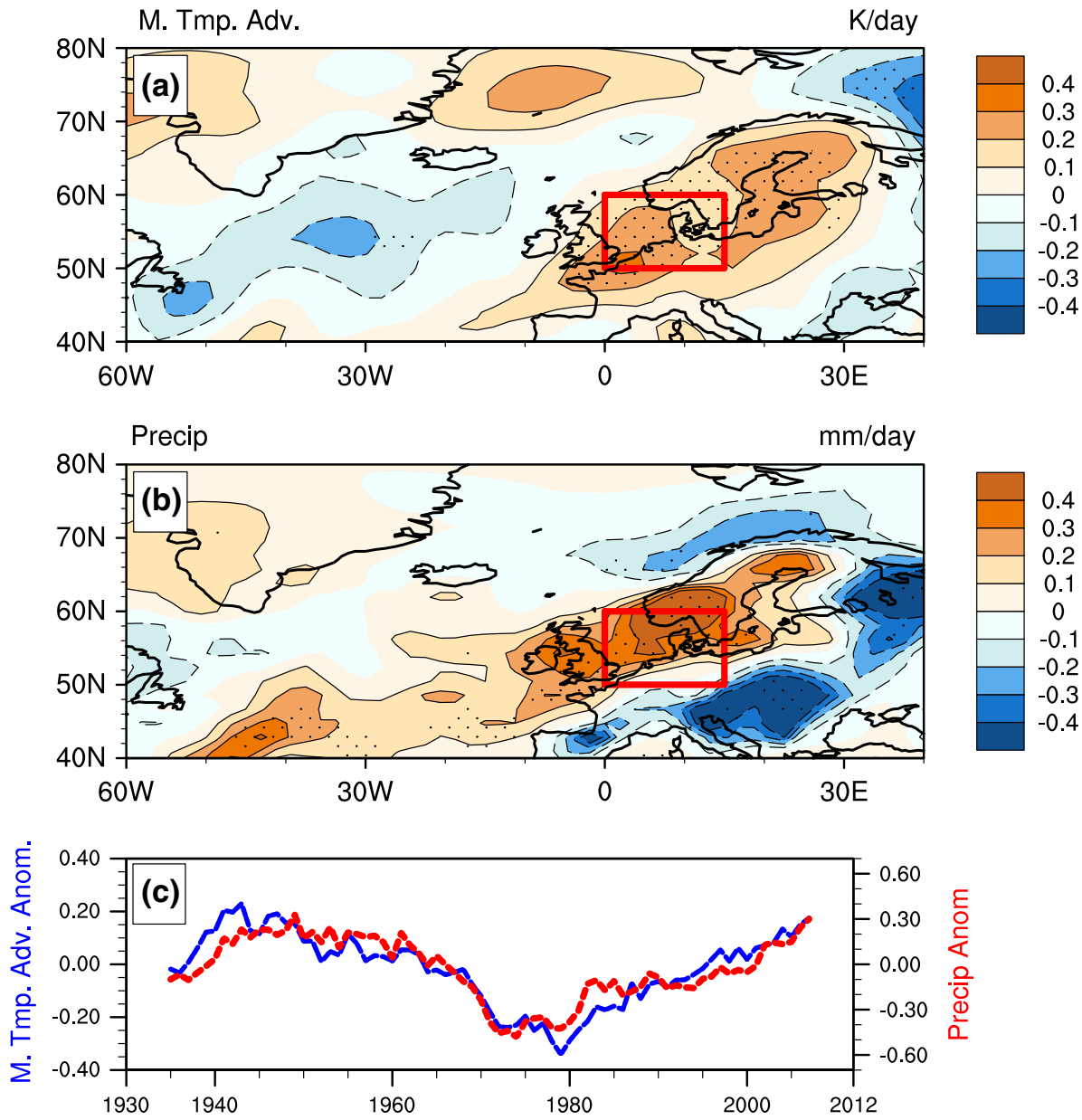

The north-ward temperature advection is mainly causing the warming of the north-western European region through advection of the subtropical warmer air.

The composites of precipitation are associated with temperature advection and show increasing values over the $\mathrm{BE}$ region, in phase with the negative surface pressure anomalies and the respective advection, and vice versa (Fig. 10b). The time series of the averaged precipitation and the meridional temperature advection over the $\mathrm{BE}$ region, show similar variations at multidecadal time scales (Fig. 10c), and are significantly correlated $(r=0.9)$. Dong et al. (2013) suggested a relation of multidecadal variations of storm tracks with the precipitation over the same region. Our results suggest that these variations of storm tracks are basically the manifestation of the NEW response which change the pressure response over this region at multidecadal time scales.

The composite of the meridional temperature advection displays major warm air advection over north-western Europe rather C-E Europe, where we identify strong multidecadal variations of temperature. Hence the temperature advection is not directly explaining the temperature variations over C-E Europe.

\subsection{Atmospheric blocking}

The composite of the outgoing long-wave radiation shows an intensive outward flux of long-wave radiation over the C-E European region (Fig. 11a). This outward flux indicates a strong localized radiative heating of the C-E European region which also shows significant reduction in precipitation (Fig. 10b). Moreover, the composite of $500 \mathrm{hPa}$ geopotential height further shows a strong high pressure anomaly over the same region which altogether indicates a blocking high characteristic. This high pressure anomaly falls under the climatological location of the European blocking region (Masato et al. 2013). A blocking high leads to warmer and drier conditions for an extended period of time. This high pressure anomaly is surrounded by low pressure systems (Fig. 11b), which is in line with the vertical structure of the NEW mode as shown in Fig. 8e. This creates a southerly flow downstream of the high pressure which blocks the westerly winds and hence favoring a European blocking-like situation over NAE region with a high just above C-E Europe. Altogether, these findings suggest that the linear baroclinic response to diabatic heating which has wave-like pattern downstream, eventually 
Fig. 11 Same as Fig. 6, but for a upward long wave radiation (OLR) at the top of atmosphere and b $500 \mathrm{hPa}$ geopotential height. Units are $\left[\mathrm{Wm}^{-2}\right]$ for OLR and [m] for $500 \mathrm{hPa}$ height. The dotted regions denote areas with significance at $95 \%$ level based on blockbootstrap test

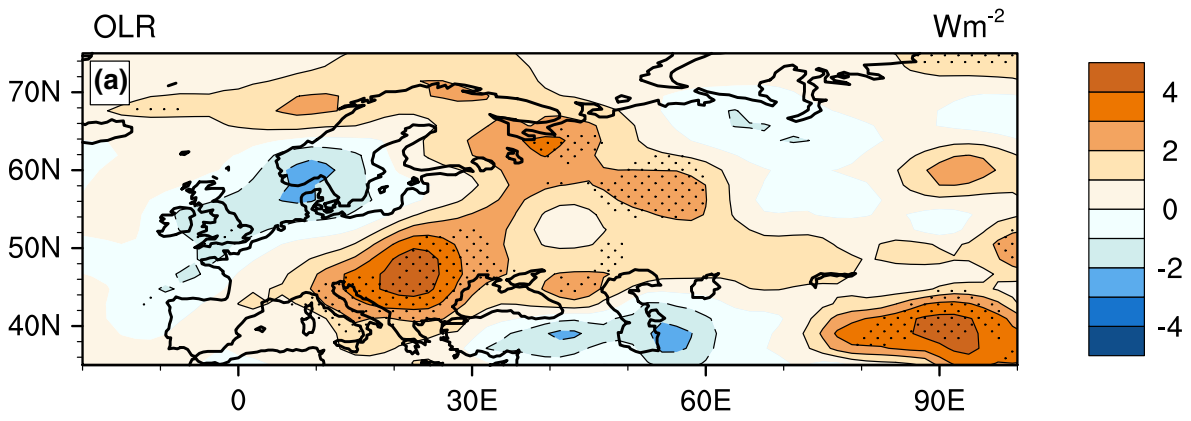

Hgt 500

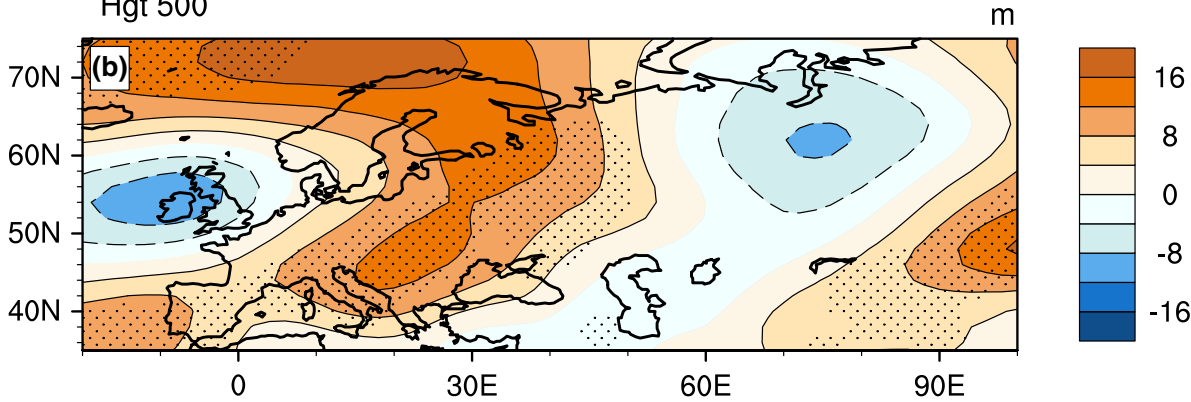

favoring blocking-like situation over the NAE region with the high pressure anomaly situated above the C-E European region during the positive phase of AMV.

To further confirm the association of blocking over C-E Europe with the NEW mode, a SVD analysis of blocking frequency is performed with respect to SLP (Fig. 12). The first mode of SVD shows the NEW mode which explains $55 \%$ covariance (Fig. 12a). The second mode shows the negative phase of SNAO, explaining $25 \%$ covariance (Fig. 12d). The blocking frequency with respect to the NEW mode shows enhanced blocking over the C-E European region (Fig. 12b). Additionally, it shows reduction of blocking over the north-western Europe where we have seen strong temperature advection leading to variation of precipitation on multidecadal time scale. The variations in blocking frequency with respect to SNAO (SVD2) is much lesser
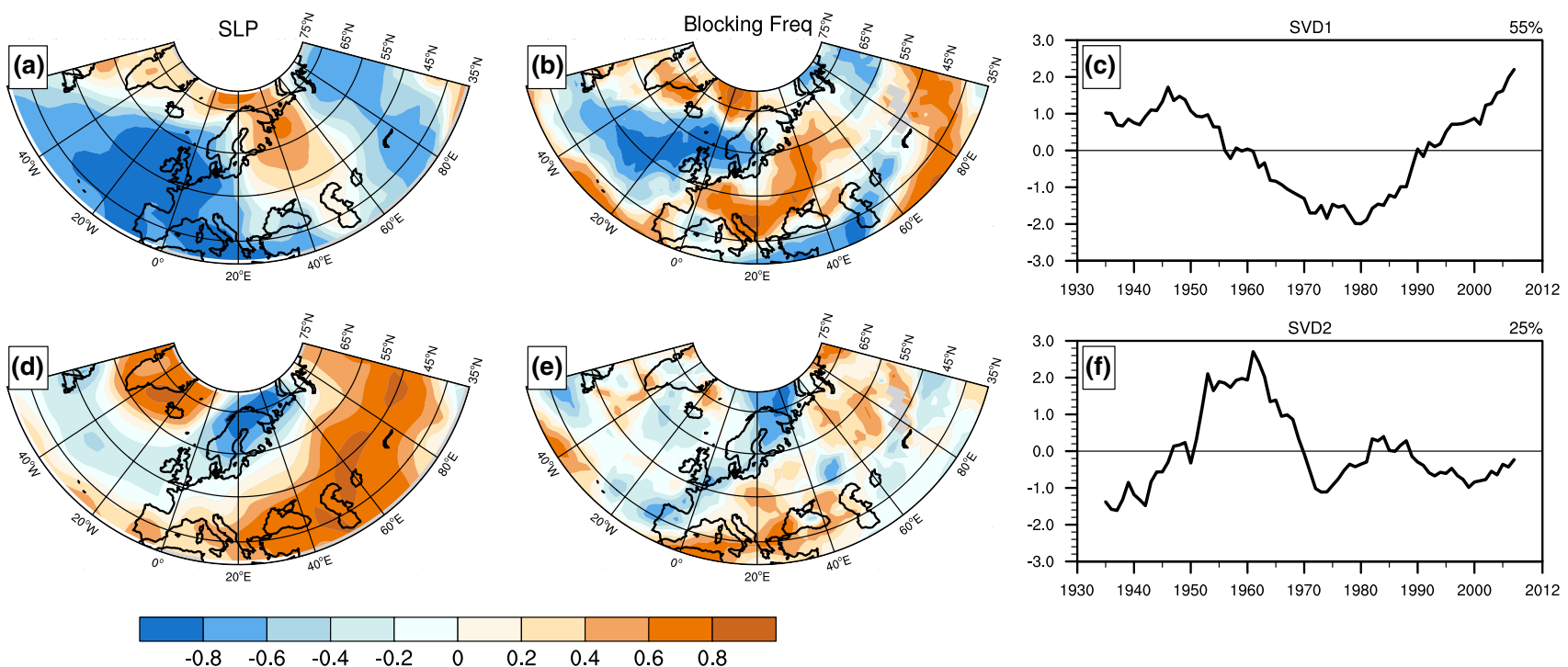

Fig. 12 SVD1 of a SLP with b blocking frequency (11 years running mean) and SVD2 of $\mathbf{d}$ SLP with e blocking frequency (11 years running mean) over the respective regions. SVD1 and SVD2 explain 55 and $25 \%$ of the total variance respectively and the spatial pat- terns represent the correlation maps. $\mathbf{c}, \mathbf{f}$ are the corresponding $\mathrm{PC} 1$ and PC2 of the SVDs representing the time series of the normalized expansion coefficients 
Fig. 13 a Velocity potential at $200 \mathrm{hPa}\left(10^{5} \mathrm{~m}^{2} \mathrm{~s}^{-1}\right)$ regressed onto the PC1 of SVD of interannual SST (MAM) and $500 \mathrm{hPa}$ geopotential (JJA). b Velocity potential at $200 \mathrm{hPa}$ regressed onto the PC1 of SVD of multidecadal SST (MAM) and $500 \mathrm{hPa}$ geopotential (JJA)
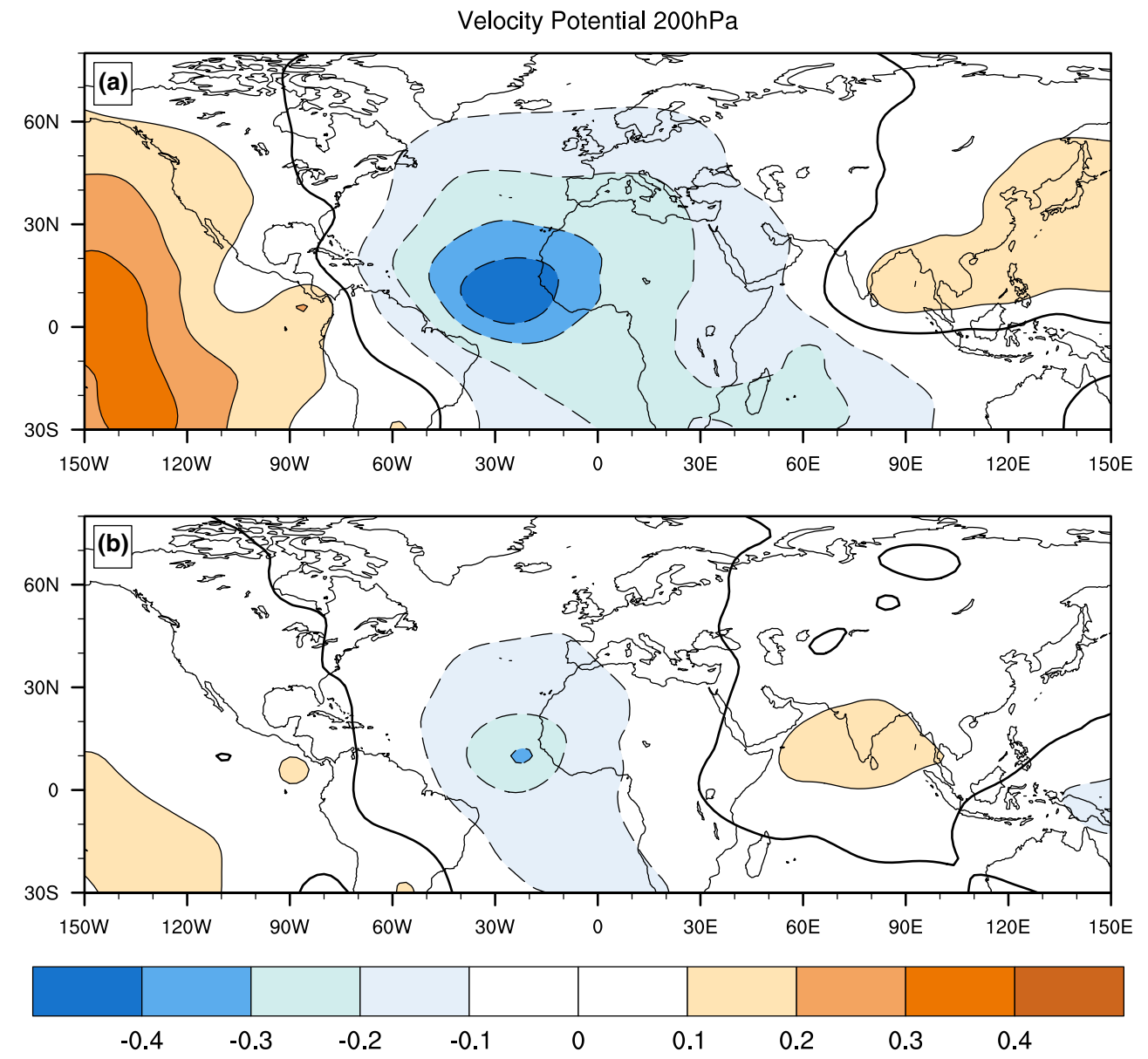

than the SVD1 of blocking frequency (Fig. 12e). It mainly shows the impact of SNAO over the southern Europe. Moreover, the time series of the PCs of the two SVDs are similar to the time series of the EOFs of SLP (Fig. 12c, f). Therefore, these results confirm that the increase in blocking events over the C-E European region is indeed related to the NEW mode and is in turn leading to the positive temperature anomalies on multidecadal time scale.

\section{Discussion}

Here, we have presented an atmospheric pathway bridging the North Atlantic AMV-like SST with the European summer climate. The pathway emerges as a direct linear response to a diabatic heating in the extra-tropical North Atlantic and appears with an East-West-like structure further downstream. This is called the North-Atlantic-European East West (NEW) mode which is affecting precipitation over the $\mathrm{BE}$ region and alter the frequency of blocking-like situations over C-E Europe. The pathway is suggested to be a response to mid-latitude forcing and thus is complementary to the recent view of a tropical forcing of the multidecadal climate over the NAE region (Terray and Cassou 2002; Hodson et al. 2010; Gastineau and Frankignoul 2015; Davini et al. 2015).

Using 20CRv2, Gastineau and Frankignoul (2015) presented an influence from the tropics to the NAE climate in summer, similar to the processes describing the wintertime atmospheric response to AMV (Terray and Cassou 2002; Davini et al. 2015). With a lead of 3 months March-AprilMay (MAM) in SST, they performed maximum covariance analysis (MCA) with the $500 \mathrm{hPa}$ geopotential pattern in summer. Using the time series of the first mode and a regression analysis on the $200 \mathrm{hPa}$ velocity potential they showed a decrease in velocity potential over the tropics associated with large scale ascending motion over the tropical Atlantic positive SST anomalies. The extra-tropical climate is thus affected by the Rossby wave propagation. However, their analysis is based on seasonal means, which could have a different characteristic than our study on decadal means. Therefore, to be conclusive with our results, we repeat the cross covariance analysis based on seasonal as well as decadal means. On seasonal means, the regression analysis of velocity potential with the first mode of SVD is similar to findings of (Gastineau and Frankignoul 2015) (Fig. 13a). For the multidecadal time scale, the first mode of SVD MAM SST shows 
an expected AMV like SST pattern (not shown) and the time series of the first mode has a correlation of 0.9 with the $\mathrm{C}-\mathrm{E}$ European SAT index. However, the regression of the time series of this first mode on velocity potential shows a much lesser amplitude of negative velocity potential compared to the analysis based on seasonal means (Fig. 13b). Moreover, it is confined to the eastern tropical Atlantic Ocean which is not in accordance to the previous findings regarding the tropical Atlantic influence over extra-tropics on multidecadal time scales (Sutton and Hodson 2007; Hodson et al. 2010; Davini et al. 2015). These figures suggest that the influence from the tropics acting on the European summer climate is rather weak on multidecadal time scale in 20CRv2. This is also in line with the analysis of the transient eddy feedback on the mean flow, which is small during summertime (Fig. 9b, d).

It should be noted that a previous study suggested a similar east-west wave-like pattern in the upper tropospheric levels $(200 \mathrm{hPa})$, but on the seasonal time scale (Saeed et al. 2014). They also point out the differences in the impact of the east-west wave-like pattern from SNAO on European summer precipitation. Given the great similarity of the upper tropospheric east-west wave-like pattern with the NEW mode, it would be worth studying if there is any relation between these two features.

The analysis in this study is based on 20CRv2, for which there is large uncertainty in the quality of the data before 1930s (Fig. 3b). This uncertainty limits our investigation to the last 83 years of data, which consists of only one full cycle of AMV. To understand the robustness and persistence of the atmospheric response from AMV, we must look into the General Circulation Models (GCM) to see whether we can reproduce the NEW response. However, previous studies show less promising results regarding the simulation of the observed AMV impact over the European region. Hodson et al. (2010) conducted a multi-model comparison experiment to investigate the effect of the multidecadal change of SST over the Atlantic Ocean on the regional climate. They investigated in 5 different atmospheric GCMs the changes in climate due to the changes in the North Atlantic SST between the warm phase from 1951-1960 to the cold phase from 1961-1990. In this analysis, Hodson et al. (2010) found a good agreement among the models regarding the changes of temperature over North America. However, for temperature over Europe, they could not find a consistent change among the atmospheric models. This can be due to the atmospheric model misrepresentation of the teleconnection pathways. On the other hand, coupled GCMs show a substantial bias in the North Atlantic (Jungclaus et al. 2013). The too strong zonal structure of the North Atlantic current and associated distribution of water masses results in displacement of the diabatic heating and associated heat fluxes. As such, further investigation is required into the capability of the atmospheric stand alone models and also the coupled GCMs to verify the proposed hypothesis of the observed atmospheric pathway from North Atlantic SSTs to European summer climate by the NEW pattern.

The relevance of the North Atlantic multidecadal variations for the European summer climate further bears prospects for decadal climate predictions. The North Atlantic has been shown to be a key region for the prediction of climate on decadal time scales. Robust prediction skill has been established for various parameters, such as temperature and heat content (Pohlmann et al. 2009; Kröger et al. 2012; Doblas-Reyes et al. 2013). Prediction skill is further assessed for climate impacts, such as for the multidecadal variability of Atlantic tropical cyclones, which have been considered to origin from the subpolar gyre region (Smith et al. 2010; Dunstone et al. 2011), or the European summer climate (Müller et al. 2012; Hermanson et al. 2014; Sienz et al. 2016). For the predictability of the European summer climate, however, the underlying processes are not yet understood. There has been some indication that the connections presented here could be relevant also for the assessment of prediction skill for European summers (Müller et al. 2012). In their prediction system prepared for CMIP5, only oceanic temperature and salinity fields are assimilated in the coupled model, with no atmospheric quantities used. Nevertheless, the correlation between the SLP and North Atlantic SST maintained an East-West-like structure similar to the NEW pattern proposed in this study. This signal, however, could not be maintained during the predictions, which may be due to the unresolved processed in the atmospheric component in their model and/or the strong bias in the North Atlantic.

And finally, during the recent positive phase of the multidecadal cycle of C-E European SAT, different parts of $\mathrm{C}-\mathrm{E}$ Europe have encountered some of the warmest summers on record (Schär et al. 2004; Luterbacher et al. 2004; Founda and Giannakopoulos 2009; Barriopedro et al. 2011). Increasing greenhouse gas concentrations and anthropogenic aerosols have been suggested to be the major drivers for this increase in the frequency of summer extreme events over the European region (Schär et al. 2004; Dong et al. 2016). However, we also find a considerable role of the multidecadal variations behind these extreme summers. To determine the frequency or return period of such extreme events, both multidecadal variations and the effect of green house gases need to be considered.

\section{Conclusions}

From our analysis of the 20CRv2 data on the mechanism behind the multidecadal variations of the C-E European summer SAT, we conclude:

- The SAT over the central to eastern (C-E) European region and the precipitation over the British Isles and north-western European (BE) region show similar multi- 
decadal variations related to the Atlantic multidecadal variability (AMV) and associated surface heat fluxes over the north-western Atlantic.

- The surface heat flux provides the source of a shallow diabatic heating which in turn generates a linear baroclinic-like atmospheric response with a surface pressure low east of the centre of the heating. This low-pressure anomaly is indicative of a quasigeostrophic response to the extra-tropical diabatic heating, in accordance with the linear quasigeostrophic theory.

- Further downstream, the SLP anomaly has an eastwest wave-like structure over the European continent. A principal component analysis of the SLP (applying a 11 years running mean) confirms the east-west wavelike NEW response pattern as the principal mode of the multidecadal variations. The NEW response is not related to the SNAO, which is the second mode of SLP variability over this region.

- The NEW response can cause strong multidecadal variations in the meridional temperature advection. The meridional temperature advection brings warm moist air from the subtropics to the extra-tropics and influences the precipitation over the BE region on multidecadal time scales.

- The east-west wave-like response in SLP can further cause a high pressure anomaly over the European region. This high pressure response is enhanced at higher altitude $(500 \mathrm{hPa})$ indicating a blocking-like situation. The analysis of the composites and the SVD analysis of the blocking frequencies confirm that the blocking over $\mathrm{C}-\mathrm{E}$ Europe have a high chance of occurrence during a positive phase of the SAT index and is related to the NEW mode. Therefore, apart from the meridional temperature advection, the NEW response mainly affects the C-E European temperature on multidecadal time scales by creating an atmospheric blocking-like situation.

Acknowledgments Open access funding provided by Max Planck Society. This research is funded by the European Unions Seventh Framework Programme (FP7/20072013) under Grant Agreement No. 308378 ENV.2012.6.1-1: Seasonal-to-decadal climate predictions towards climate services http://www.specs-fp7.eu/ and by the German Federal Ministry for Education and Research (BMBF) project MiKlip (Ref. No. 01LP1519A). This research is supported by the Cluster of Excellence 'CliSAP' (EXC177), University of Hamburg, funded through the German Science Foundation (DFG) and by the Max Planck Society for the Advancement of Science. The Twentieth Century Reanalysis V2 data is provided by the NOAA/OAR/ESRL PSD, Boulder, Colorado, USA, from their website http://www.esrl. noaa.gov/psd/. I am thankful to Frank Sienz for providing his help regarding statistical significance tests. Johann Jungclaus is thanked for his valuable comments which improved various parts of the draft. I acknowledge Jochem Marotzke and Dallas Murphy for helping me improving the clarity and the flow of writing in the paper. I would like to thank two anonymous reviewers for their thorough and constructive comments which considerably enhanced the quality of the paper.
Open Access This article is distributed under the terms of the Creative Commons Attribution 4.0 International License (http://creativecommons.org/licenses/by/4.0/), which permits unrestricted use, distribution, and reproduction in any medium, provided you give appropriate credit to the original author(s) and the source, provide a link to the Creative Commons license, and indicate if changes were made.

\section{References}

Bader J, Flügge M, Kvamsto NG, Mesquita MDS, Voigt A (2013) Atmospheric winter response to a projected future Antarctic seaice reduction: a dynamical analysis. Clim Dyn 40:27072718. doi:10.1007/s00382-012-1507-9

Barriopedro D, Fischer EM, Luterbacher J, Trigo RM, Garca-Herrera R (2011) The hot summer of 2010: redrawing the temperature record map of Europe. Science 332(6026):220-224. doi:10.1126/ science. 1201224

Bladé I, Liebmann B, Fortun D, van Oldenborgh GJ (2012) Observed and simulated impacts of the summer NAO in Europe: implications for projected drying in the mediterranean region. Clim Dyn 39:709-727. doi:10.1007/s00382-011-1195-x

Bretherton CS, Smith C, Wallace JM (1992) An intercomparison of methods for finding coupled patterns in climate data. J Clim 5:541560. doi:10.1175/1520-0442(1992) 005<0541:AIOMFF>2.0.CO;2

Compo GP, Whitaker JS, Sardeshmukh PD (2006) Feasability of a 100-year reanalysis using only surface pressure data. Bull Am Meteorol Soc 87:175-190. doi:10.1175/BAMS-87-2-175

Compo GP, Whitaker JS, Sardeshmukh PD, Matsui N, Allan RJ, Yin X, Gleason BE, Vose RS, Rutledge G, Bessemoulin P, Brönnimann S, Brunet M, Crouthamel RI, Grant AN, Groisman PY, Jones PD, Kruk MC, Kruger AC, Marshall GJ, Maugeri M, Mok HY, Nordli $\varnothing$, Ross TF, Trigo RM, Wang XL, Woodruff SD, Worley SJ (2011) The twentieth century reanalysis project. Q J R Meteorol Soc 137:1-28. doi:10.1002/qj.776

Czaja A, Frankignoul C (2002) Observed impact of Atlantic SST anomalies on the North Atlantic Oscillation. J Clim 15(6):606-623. doi:10.1175/1520-0442(2002) 015<0606:OIOASA>2.0.CO;2

Davini P, von Hardenberg J, Corti S (2015) Tropical origin for the impacts of the Atlantic multidecadal variability on the Euro-Atlantic climate. Environ Res Lett 10(9):094,010. doi:10.1088/1748-9326/10/9/094010

Doblas-Reyes F, Andreu-Burillo I, Chikamoto Y, Garca-Serrano J, Guemas V, Kimoto M, Mochizuki T, Rodrigues L, van Oldenborgh G (2013) Initialized near-term regional climate change prediction. Nat Commun. doi:10.1038/ncomms2704

Dong B, Sutton RT, Woollings T, Hodges K (2013) Variability of the North Atlantic summer storm track: meachanisms and impacts on the European climate. Environ Res Lett 8(034):037. doi:10.1088/1748-9326/8/3/034037

Dong B, Sutton RT, Shaffrey L (2016) Understanding the rapid summer warming and changes in temperature extremes since the mid-1990s over Western Europe. Clim Dyn. doi:10.1007/s00382-016-3158-8

Dong BW, Sutton RT, Woollings T (2012) The extreme European summer 2012. Bull Am Meteorol Soc 94(9):S28-S32. doi:10.1175/BAMS-D-13-00085.1

Duchon CE (1979) Lanczos filtering in one and two dimensions. J Appl Meteorol 18:1016-1022. doi:10.1175/1520-0450(1979) $018<1016$ :LFIOAT $>2.0 . \mathrm{CO} ; 2$

Dunstone NJ, Smith DM, Eade R (2011) Multi-year predictability of the tropical Atlantic atmosphere driven by the high latitude North Atlantic Ocean. Geophys Res Lett. doi:10.1029/2011GL047949 
Folland CK, Knight J, Linderholm HW, Fereday D, Ineson S, Hurrell JW (2009) The summer North Atlantic Oscillation: past, present, and future. J Clim 22:1082-1103. doi:10.1175/2008JCLI2459.1

Founda D, Giannakopoulos C (2009) The exceptionally hot summer of 2007 in Athens, Greece-a typical summer in the future climate. Global Planet Change 67:227-236. doi:10.1016/j. gloplacha.2009.03.013

Gastineau G, Frankignoul C (2015) Influence of the North Atlantic SST variability on the atmospheric circulation during the twentieth century. J Clim 28:1396-1416. doi:10.1175/JCLI-D-14-00424.1

Gulev SK, Latif M, Keenlyside N, Park W, Koltermann KP (2013) North Atlantic Ocean control on surface heat flux on multidecadal timescales. Nature 499:464-467. doi:10.1038/nature12268

Harris I, Jones PD, Osborn TJ, Lister DH (2014) Updated high-resolution grids of monthly climatic observationsThe CRU TS 3.1 dataset. Int J Climatol doi:10.1002/joc.3711

Hermanson L, Eade R, Robinson NH, Dunstone NJ, Andrews MB, Knight JR, Scaife AA, Smith DM (2014) Forecast cooling of the Atlantic subpolar gyre and associated impacts. Geophys Res Lett 41:5167-5174. doi:10.1002/2014GL060420

Hodson DLR, Sutton RT, Cassou C, Keenlyside N, Okumura Y, Zhou T (2010) Climate impacts of recent multidecadal changes in Atlantic Ocean Sea Surface Temperature: a multimodel comparison. Clim Dyn 34(7-8):1041-1058. doi:10.1007/ s00382-009-0571-2

Hoskins BJ, Karoly DJ (1981) The steady linear response of a spherical atmosphere to thermal and orographic forcing. J Atmos Sci 38:1179-1196. doi:10.1175/1520-0469(1981) 038<1179:TSLR $\mathrm{OA}>2.0 . \mathrm{CO} ; 2$

Hoskins BJ, James IN, White GH (1983) The shape, propagation and mean-flow interaction of large scale weather systems. J Atmos Sci 40:1595-1612

Jungclaus J, Fischer N, Haak H, Lohmann K, Marotzke J, Matei D, Mikolajewicz U, Notz D, Storch J (2013) Characteristics of the ocean simulations in the Max Planck Institute Ocean Model (MPIOM) the ocean component of the MPI-Earth system model. J Adv Model Earth Syst 5(2):422-446. doi:10.1002/jame.20023

Knight JR, Folland CK, Scaife AA (2006) Climate impacts of the Atlantic Multidecadal Oscillation. Geophys Res Lett 33(L17):706. doi:10.1029/2006GL026242

Kröger J, Müller WA, von Storch JS (2012) Impact of different ocean reanalyses on decadal climate prediction. Clim Dyn 39(34):795-810. doi:10.1007/s00382-012-1310-7

Krueger O, Schenk F, Feser F, Weisse R (2013) Inconsistencies between long-term trends in storminess derived from the 20CR reanalysis and observations. J Clim 26:868874. doi:10.1175/ JCLI-D-12-00309.1

Kushnir Y (1994) Interdecadal variations in North Atlantic sea surface temperature and associated atmospheric conditions. J Clim 7:141-157. doi:10.1175/1520-0442(1994) 007<0141:IVINAS >2. $0 . \mathrm{CO} ; 2$

Kushnir Y, Held IM (1996) Equilibrium atmospheric response to North Atlantic SST anomalies. J Clim 9(6):1208-1220. doi:10.1175/1520-0442(1996) 009<1208:EARTNA>2.0.CO;2

Kushnir Y, Robinson WA, Blade I, Hall NMJ, Peng S, Sutton R (2002) Atmospheric GCM response to extratropical SST anomalies: synthesis and evaluation. J Clim 15:2233-2256. doi:10.1175/1520-0442(2002) 015<2233:AGRTES>2.0.CO;2

Luterbacher J, Dietrich D, Xoplaki E, Grosjean M, Wanner H (2004) European seasonal and annual temepearture variability trends and extremes since 1500. Science 303(5663):1499-1503. doi:10.1126/science.1093877

Mak M, Cai M (1989) Local barotropic instability. J Atmos Sci 46(21):3289-3311. doi:10.1175/1520-0469(1989) $046<3289: \mathrm{LBI}>2.0 . \mathrm{CO} ; 2$
Masato G, Hoskins BJ, Woollings T (2013) Winter and summer Northern Hemisphere blocking in CMIP5 models. J Clim 26(18):7044-7059. doi:10.1175/JCLI-D-12-00466.1

Matthews AJ, Kiladis GN (1999) Interaction between ENSO, transient circulation and tropical convection over the Pacific. J Clim 12:3062-3086. doi:10.1175/1520-0442(1999) 012<3062:IBETC $\mathrm{A}>2.0 . \mathrm{CO} ; 2$

Mestas-Nunez AM (2000) Orthogonality properties of rotated empirical modes. Int J Climatol 20:1509-1516. doi:10.1002/10970088(200010)20:12<1509:AID-JOC553>3.0.CO;2-Q

Müller WA, Baehr J, Haak H, Jungclaus JH, Krger J, Matei D, Notz D (2012) Forecast skill of multi-year seasonal means in the decadal prediction system of the Max Planck Institute for Meteorology. Geophys Res Lett 39(L22):707. doi:10.1029/2012GL053326

Müller WA, Pohlmann H, Sienz F, Smith D (2014) Decadal climate predictions for the period 1901-2010 with a coupled climate model. Geophys Res Lett 41:2100-2107. doi:10.1002/2014GL059259

North GR, Bell TL, Cahalan RF, Moeng FJ (1982) Sampling errors in the estimation of empirical orthogonal functions. Mon Weather Rev 110:699-706. doi:10.1175/1520-0493(1982)110<0699:SEI TEO $>2.0 . \mathrm{CO} ; 2$

Peng S, Whitaker JS (1999) Mechanisms determining the atmospheric response to midlatitude SST anomalies. J Clim 12:1393-1408. doi:10.1175/1520-0442(1999) 012<1393:MDTART>2.0.CO;2

Pohlmann H, Jungclaus JH, Köhl A, Stammer D, Marotzke J (2009) Initializing decadal climate predictions with the GECCO oceanic synthesis: effects on the North Atlantic. J Clim 22:3926-3938. doi:10.1175/2009JCLI2535.1

Raible CC, Ziv B, Saaroni H, Wild M (2010) Winter synoptic-scale variability over the Mediterranean Basin under future climate coconditions simulated by the ECHAM5. Clim Dyn 35:473-488. doi:10.1007/s00382-009-0678-5

Rayner NA, Parker DE, Horton EB, Folland CK, Alexander LV, Rowell DP, Kent EC, Kaplan A (2003) Global analysis of sea surface temperature, sea ice, and night marine air temperature since the late nineteenth century. J Geophys Res 108(D14):4407. doi:10.1 029/2002JD002670

Robson J, Sutton R, Lohmann K, Smith D, Palmer MD (2012) Causes of the rapid warming of the North Atlantic Ocean in the mid1990s. J Clim 25:4116-4134. doi:10.1175/JCLI-D-11-00443.1

Saeed S, Lipzig NV, Müller WA, Saeed F, Zanchettin D (2014) Influence of the circumglobal wave-train on European summer precipitation. Clim Dyn 43:503-515. doi:10.1007/ s00382-013-1871-0

Schär C, Vidale PL, Luethi D, Frei C, Haeberli C, Liniger MA, Appenzeller C (2004) The role of increasing temperature variability in European Summer heatwaves. Nature 427:332-336. doi:10.1038/nature 02300

Scherrer SC, Croci-Maspoli M, Schwierz C, Appenzeller C (2006) Two-dimensional indices of atmospheric blocking and their statistical relationship with winter climate patterns in the EuroAtlantic region. Int J Climatol 26:233-249. doi:10.1002/joc.1250

Schreck CJ, Shi L, Kossin JP, Bates JJ (2013) Identifying the MJO, equatorial waves, and their impacts using 32 years of HIRS upper-tropospheric water vapor. J Clim 26:1418-1431. doi:10.1175/JCLI-D-12-00034.1

Sienz FH, Müller WA, Pohlmann H (2016) Ensemble size impact on the decadal predictive skill assessment. Meteorol Z. doi:10.1127/ metz/2016/0670

Smagorinsky J (1953) The dynamical influence of large-scale heat sources and sinks on the quasi-stationary mean motions of the atmosphere. Q J R Meteorol Soc 79:342-366

Smith DM, Eade R, Dunstone NJ, Fereday D, Murphy JM, Pohlmann H, Scaife AA (2010) Skilful multi-year predictions of Atlantic hurricane frequency. Nat Geosci 3:846-849. doi:10.1038/NGEO1004 
Sutton RT, Dong B (2012) Atlantic Ocean influence on a shift in European climate in 1990s. Nat Geosci 5:788-792. doi:10.1038/ ngeo1595

Sutton RT, Hodson DL (2007) Climate response to basin-scale warming and cooling of the North Atlantic Ocean. J Clim 20(5):891907. doi:10.1175/JCLI4038.1

Sutton RT, Hodson DLR (2005) Atlantic Ocean forcing of North American and European summer climate. Science 309(5731):115-118. doi:10.1126/science. 1109496

Terray L, Cassou C (2002) Tropical Atlantic Sea surface temperature forcing of quasi-decadal climate variability over the North Atlantic-European region. J Clim 15:31703187. doi:10.1175/15200442(2002) 015<3170:TASSTF>2.0.CO;2
Whitaker JS, Compo GP, Wei X, Hamill TM (2004) Reanalysis without radiosondes using ensemble data assimilation. Mon Weather Rev 132:1190-1200. doi:10.1175/1520-0493(2004) 132<1190:RWRUED>2.0.CO;2

Woollings T, Czuchnicki C, Franke C (2014a) Twentieth century North Atlantic jet variability. Q J R Meteorol Soc 140:783-791. doi:10.1002/qj.2197

Woollings T, Franzke C, Hodson DLR, Dong B, Barnes EA, Raible CC, Pinto JG (2014b) Contrasting interannual and multidecadal NAO variability. Clim Dyn. doi:10.1007/s00382-014-2237-y 